\title{
Physicochemical characterization of chitosan extracted from Metapenaeus stebbingi shells
}

\author{
Aygul Kucukgulmez ${ }^{\mathrm{a}, *}$, Mehmet Celik ${ }^{\mathrm{a}}$, Yasemen Yanar $^{\mathrm{a}}$, Didem Sen ${ }^{\mathrm{b}}$, Hurriyet Polat ${ }^{\mathrm{b}}$, A. Eslem Kadak ${ }^{\mathrm{a}}$ \\ ${ }^{a}$ Cukurova University, Faculty of Fisheries, Department of Fishing and Fish Processing Technology, Adana, Turkey \\ ${ }^{\mathrm{b}}$ Izmir Institute of Technology, Faculty of Science, Department of Chemistry, Izmir, Turkey
}

\section{A R T I C L E I N F O}

\section{Article history:}

Received 28 June 2010

Received in revised form 15 October 2010

Accepted 25 November 2010

Available online 1 December 2010

\section{Keywords:}

Chitosan

Metapenaeus stebbingi

Physicochemical characteristics

\begin{abstract}
A B S T R A C T
In this study, chitosan was extracted from Metapenaeus stebbingi shells. In order to determine physicochemical characteristics of the extracted chitosan, the yield, moisture and ash contents, degree of deacetylation, molecular weight, water and fat binding capacities, apparent viscosity and colour properties were measured using a variety of techniques including Fourier transform infrared spectroscopy, scanning electron microscopy and X-ray diffraction. In addition, the physicochemical characteristics of the chitosan extracted from M. stebbingi shells were compared to commercial chitosan. The degree of deacetylation was calculated by the titration method and elemental analysis. The molecular weight was determined by viscosimetric methods. The results of the study indicate that shrimp shells are a rich source of chitosan as $17.48 \%$ of the shell's dry weight is consisted of this material. Extracted chitosan exhibited a lower molecular weight, higher degree of deacetylation, higher viscosity and higher water and fat binding capacities compared to the commercial chitosan.
\end{abstract}

(c) 2010 Elsevier Ltd. All rights reserved.

\section{Introduction}

Chitin ( $\beta$-1,4-poly- $N$-acetyl-D-glucosamine) is the second most common polymer after cellulose in nature, existing in the shells of crustaceans like crab, shrimp and lobster as well as in the exoskeleton of marine zooplankton, the cuticle of insects and the cell walls of fungicide. Chitosan (poly- $\beta$-1,4-2-amino-2-deoksi- $\beta$-D-glukopiranoz) is derived by deacetylation of chitin (Knorr, 1984; No \& Meyers, 1989; Ruiz-Herrera, 1978). Due to its biodegradability, biocompatibility, nontoxic and wound healing properties and haemostatic activity, chitosan has received increased attention as one of the promising renewable polymeric materials for various applications (Knorr, 1984; Yen, Yang, \& Mau, 2009). It is commonly used in different sectors including especially food, chemistry, biotechnology, agriculture, veterinary, cosmetic, medicine, dentistry, environmental protection, textile, paper making and packaging (Coward-Kelly, Agbogbo, \& Holtzapple, 2006; Duarte de Holanda \& Netto, 2006; Healy, Green, \& Healy, 2003; Lamarque et al., 2005; Seo, King, \& Prinyawiwatkul, 2007; Shahidi \& Synowiecki, 1991).

Chitosan is commercially produced from crustaceans in general, and shells of shrimp are quite important amongst them. Metapenaeus stebbingi, caught from the Aegean and Mediterranean Sea, is a highly demanded crustacean both in Turkey and abroad. However,

\footnotetext{
* Corresponding author. Tel.: +90 322338 6646; fax: +90 3223386439 .

E-mail address: akucukgulmez@cu.edu.tr (A. Kucukgulmez).
}

there is no detailed study in Turkey regarding the use of shells of this shrimp species. The waste amount of the shell not used in the factories presents a big potential. This waste is normally likely to affect human health adversely as it could lead to environmental pollution. For this reason, the utilisation of this source would not only be beneficial to the industry, but to the community health as well.

The aim of the present study was to perform a characterization of the chitosan extracted from $M$. stebbingi shells with chemical methods. In the characterization of the chitosan, the yield, moisture and ash contents, degree of deacetylation, molecular weight, water and fat binding capacities, apparent viscosity, colour properties were measured. In addition, chitosan extracted from M. stebbingi was compared to commercial chitosan.

\section{Materials and methods}

\subsection{Materials}

Shell materials were obtained from the wastes of $M$. stebbingi. Fresh samples of shrimp processing discards, comprising intact cephalothorax and abdominal exoskeleton, were collected from a local shrimp factory. Representative shrimp wastes were selected, packed in plastic bags and stored at $-20^{\circ} \mathrm{C}$ before and during transportation to the laboratory. Shells were completely separated from the shrimp wastes in laboratory, washed in pure water and dried at $60{ }^{\circ} \mathrm{C}$. 


\subsection{Extraction of chitosan}

Chitosan was extracted by the method of Chang, Tsai, Lee, and Fu (1997). Deproteinization and demineralization steps were carried out with $2.5 \mathrm{~N} \mathrm{NaOH}$ at $65^{\circ} \mathrm{C}$ for $6 \mathrm{~h}$ and $1.7 \mathrm{~N} \mathrm{HCl}$ at $25^{\circ} \mathrm{C}$ for $6 \mathrm{~h}$, respectively. The chitin residue was treated with nine volumes of hydrogen peroxide and dried at $90^{\circ} \mathrm{C}$ for $2 \mathrm{~h}$. Chitosan was prepared by alkali treatment of chitin using $50 \%(\mathrm{w} / \mathrm{v}) \mathrm{NaOH}$ in distiled water at $120^{\circ} \mathrm{C}$. The reactants were filtered, washed with deionized water to neutral $\mathrm{pH}$ and dried at $90^{\circ} \mathrm{C}$ for $2 \mathrm{~h}$.

\subsection{Characterization of chitosan}

\subsubsection{Yield, moisture and ash contents}

The chitosan yield was calculated by comparing the weight measurements of the raw material to the chitosan obtained after treatment. The moisture was determined after drying samples for $24 \mathrm{~h}$ at $105^{\circ} \mathrm{C}$, and the ash content was determined by heating at $530{ }^{\circ} \mathrm{C}$ for $20 \mathrm{~h}$.

\subsubsection{Determination of the deacetylation degree}

2.3.2.1. Potentiometric titration. The degree of deacetylation (DD) of chitosan was determined by a potentiometric titration method. $250 \mathrm{mg}$ portion of chitosan were dissolved in $10 \mathrm{ml}$ of $0.30 \mathrm{M}$ $\mathrm{HCl}$ and after being diluted to $50 \mathrm{ml}$ with ultrapure water, it was titrated with $0.10 \mathrm{M} \mathrm{NaOH}$. The consumed volume of $\mathrm{NaOH}$ solution, which corresponds to the amount of amine groups in chitosan, is obtained from the difference between two inflection points of acid-base titration (Tolaimate et al. (2000)).

2.3.2.2. Elemental analysis. A LECO CHNS-932 elemental analysis apparatus was used to determine the amount of $C$ and $N$ in chitosan. In this case, samples were heated to a temperature of $1000^{\circ} \mathrm{C}$ and approximately $2 \mathrm{mg}$ of chitosan was placed inside a silver capsule and dropped into the CHNS-932 furnace, where it was completely combusted. This instrument relies upon infrared detection to measure the weight percent of carbon, while nitrogen was measured by thermal conductivity detection. The DD of chitosan was determined by the formula below (Kasaai, Arul, \& Charlet, 2000):

$\mathrm{DD}=\frac{\mathrm{C} / \mathrm{N}-5.145}{6.861-5.145} \times 100$

\subsubsection{Molecular weight determination}

For the determination of viscosity-average molecular weight, eight chitosan solutions at different concentrations were prepared in $0.2 \mathrm{M} \mathrm{NaCl} / 0.1 \mathrm{M} \mathrm{AcOH}$. The solvent was chosen according to the deacetylation degree results from the study of Wang et al. (2006). The efflux times of the solutions were measured in triplicate using an Ubbelohde capillary viscometer in a constant-temperature water bath at $25^{\circ} \mathrm{C}$. The running times of the solution and solvent were recorded as seconds (s) and used to calculate intrinsic viscosity.

The Mark-Houwink equation $[\eta]=K M^{\alpha}$ was used to calculate the molecular weight of chitosan. In this equation $[\eta]$ defines the intrinsic viscosity, $K$ and $\alpha$ are constants the values of which depend on the nature of the polymer and the solvent, as well as on the temperature. $M$ is relative molecular weight. Values of $K$ and $\alpha$ were $1.64 \times 10^{-30} \times \mathrm{DD}^{14}(\mathrm{ml} / \mathrm{g})$ and $1.02 \times 10^{-2} \times \mathrm{DD}+1.82$, respectively, and DD is the degree of deacetylation of chitosan expressed as the percentage (Wang et al., 2006).

\subsubsection{Apparent viscosity}

A chitosan solution was prepared in $1 \%(\mathrm{v} / \mathrm{v})$ acetic acid at $1 \%$ $(\mathrm{w} / \mathrm{v})$ concentration on a moisture-free basis. The chitosan solution was then filtered using filter paper to remove insoluble materials.
The viscosity of chitosan was determined with an AMVn Automated Micro Viscometer (Anton Paar, Graz, Austria). Measurements were made in triplicate at $20,25,30,35$ and $40^{\circ} \mathrm{C}$. Values were reported in centipoises units (cP).

\subsubsection{Colour measurement}

The chitosan sample was put in a transparent petri dish. The colour of chitosan was measured using a Hunter lab (Hunter Associates Laboratory, Inc., Reston, VA, USA), which was standardised with a calibration white plate $(X=78.83, Y=83.79, Z=88.60$, $L^{*}=3.47, a^{*}=-0.12, b^{*}=-0.32$ ). The results were recorded as $L^{*}$, $a^{*}, b^{*}$. Chroma, hue and whiteness values of the sample were calculated based on the following equations (Seo et al., 2007):

Chroma $=\left(a^{* 2}+b^{* 2}\right)^{1 / 2}$

Hue $=\operatorname{Arctan}\left(b^{*} / a^{*}\right)$

Whiteness $=100-\left[\left(100-L^{*}\right)^{2}+a^{* 2}+b^{* 2}\right]^{1 / 2}$

\subsubsection{Water and fat binding capacity}

Water binding capacity (WBC) and fat binding capacities (FBC) of chitosan were measured using a modified method of Wang and Kinsella (1976). Water and fat absorption were initially carried out by weighing a centrifuge tube containing $0.5 \mathrm{~g}$ of sample, adding $10 \mathrm{ml}$ of water or soybean oil and mixing on a vortex mixer for $1 \mathrm{~min}$ to disperse the sample. The contents were left at ambient temperature for $30 \mathrm{~min}$ with shaking for $5 \mathrm{~s}$ every $10 \mathrm{~min}$ and centrifuged at $3500 \mathrm{rpm}$ for $25 \mathrm{~min}$. After the supernatant was decanted, the tube was weighed again. WBC and FBC were determined as follows:

WBC $(\%)=$ Water bound $/$ sample weight $\times 100$;

FBC $(\%)=$ Fat bound $/$ sample weight $\times 100$

\subsubsection{Fourier transform infrared spectroscopy (FTIR)}

IR characterization of chitosan was performed with a Nicolet Magna 550 FT-IR instrument. Chitosan samples were prepared in the forms of thin film (Niamsa \& Baimark 2009). For the preparation, $2 \% \mathrm{w} / \mathrm{v}$ chitosan was dissolved in $2 \%$ acetic acid solution $(\mathrm{AcOH})$, poured on a petri dish, and finally dried at $60{ }^{\circ} \mathrm{C}$ for $16 \mathrm{~h}$ under vacuum. In this preparation method, the important thing is the equal film thickness for all samples. The spectra of the chitosan samples (in the forms of thin film) were obtained with a frequency range of $4000-400 \mathrm{~cm}^{-1}$ at $4 \mathrm{~cm}^{-1}$ resolution and 16 scan.

\subsubsection{Scanning electron microscopy (SEM)}

SEM characterization was carried out using a Philips XL-30S FEG type instruments in a vacuum environment. Prior to analysis, the chitosan was sprinkled onto adhesive $\mathrm{Al}$ or $\mathrm{C}$ tapes and was supported on metallic discs and coated with Au. Images of the sample surfaces were recorded at different areas and magnifications.

\subsubsection{X-ray diffraction $(X R D)$}

X-ray diffraction data were collected on a Philipps X'Pert Pro diffractometer using $\mathrm{Cu} \mathrm{K} \mathrm{K}_{\alpha 1}$ radiation $(\lambda=0.154056 \mathrm{~nm})$ in 5$45 \theta$ values. Chitosan was prepared by compressing it in the cassette sample holder without any adhesive substances.

\subsection{Statistical analysis}

Analysis of variance was performed using the SPSS statistical package program (SPSS 15.0 for Windows, SPSS Inc., Chicago, IL, USA). 


\section{Results and discussion}

The present study represents the first attempt to investigate various physicochemical properties of chitosan extracted from $M$. stebbingi shells. The results of yield, moisture, ash, deacetylation degree, molecular weight, water and fat binding capacities of chitosan extracted from $M$. stebbingi shells and commercial chitosan are shown in Table 1.

The chitosan yield of $M$. stebbingi shells, being about $17.5 \%$, justifies its use as an economic way of producing chitosan on an industrial scale due to the availability of $M$. stebbingi and the low cost of the sources. Similar to the present study, a chitosan yield of $14.6 \%$ was reported from the carapax of Penaeus monodon (Hongpattarakere \& Riyaphan, 2008). When the commercial chitosan was compared to the extracted chitosan, similarities were found in moisture (1.07-1.33\%, respectively) and ash contents (0.59$0.61 \%$, respectively) $(p>0.05)$. The results show similarities with the moisture and ash content of chitosan obtained from different sources (Artemia urmiana, snow crab processing) (Kamil, Jeon, \& Shahidi, 2002; Tajik, Moradi, Rohani, Efrani, \& Jalali, 2008).

The deacetylation degree, molecular weight and also the order of its repetitive units are important parameters for chitosan, as they affect its properties (Lamarque et al., 2005). The deacetylation degree of chitosan is important for its use in the industry. From this regard, certain researchers (Li, Dunn, Grandmaison, \& Goosen, 1992; Muzzarelli \& Rocchetti, 1985) suggested that the term chitosan should be used when the degree of deacetylation is above $<70 \%$. In the present study, the deacetylation degrees of the commercial chitosan and the extracted chitosan were determined as $86.92 \%$ and $92.19 \%$, respectively, by the elemental analysis and potentiometric titration.

The molecular weight of chitosan is one of the most important properties as it considerably affects the physicochemical and functional properties (Yen et al., 2009). The molecular weight of extracted chitosan $(2.20 \mathrm{kDa})$ was lower than commercial chitosan (3.52 kDa). The difference in the molecular weight is caused by the difference in the deacetylation degree, and the different sources of the chitosan. In addition, several factors in the production of chitosan, such as the high temperature, concentration of alkali, reaction time, previous treatment of the chitin, particle size, chitin concentration, dissolved oxygen concentration and shear stress may also influence the molecular weight of chitosan (Guo, Kikuchi, Matahira, Sakai, \& Ogawa, 2002; Li et al., 1992; Nemtsev, Gamzazade, Rogozhin, Bykova, \& Bykov, 2002; Oh, Kim, Chang, \& Kim, 2001).

The water binding (WBC) and fat binding capacities (FBC) of commercial chitosan are lower than the extracted chitosan. Water and fat binding capacities of different commercial chitosans were reported as $458-805 \%$ and $314-535 \%$, respectively, by Cho, No, and Meyers (1998). WBC and FBC of six commercial chitosan products observed by No, Lee, and Meyers (2000) were in the range of

Table 1

Physicochemical characteristics of extracted and commercial chitosan (mean \pm standard deviation of triplicate determinations).

\begin{tabular}{lcc}
\hline & Extracted chitosan & Commercial chitosan \\
\hline Yields (\%) & $17.48 \pm 0.64$ & - \\
Moisture (\%) & $1.33 \pm 0.08$ & $1.07 \pm 0.09$ \\
Ash (\%) & $0.61 \pm 0.03$ & $0.59 \pm 0.07$ \\
Deacetylation degree (\%) & $92.19 \pm 2.56$ & $86.92 \pm 1.62^{\mathrm{b}}$ \\
Molecular weight (kDa) & $2.20 \pm 0.03$ & $3.52 \pm 0.02^{\mathrm{a}}$ \\
Water binding capacity (\%) & $712.99 \pm 11.98$ & $492.67 \pm 10.14^{\mathrm{a}}$ \\
Fat binding capacity (\%) & $531.15 \pm 12.26$ & $383.04 \pm 10.02^{\mathrm{a}}$ \\
\hline
\end{tabular}

a Indicates a significant difference between two groups $(p<0.01)$.

b Indicates a significant difference between two groups $(p<0.05)$.
Table 2

Apparent viscosities (cP) of extracted and commercial chitosan at various temperatures (mean \pm standard deviation of triplicate determinations).

\begin{tabular}{lll}
\hline$\left({ }^{\circ} \mathrm{C}\right)$ & Extracted chitosan & Commercial chitosan \\
\hline 20 & $56.52 \pm 0.14$ & $38.21 \pm 0.03^{\mathrm{a}}$ \\
25 & $46.14 \pm 0.07$ & $31.88 \pm 0.00^{\mathrm{a}}$ \\
30 & $38.18 \pm 0.02$ & $27.09 \pm 0.01^{\mathrm{a}}$ \\
35 & $31.69 \pm 0.06$ & $23.30 \pm 0.00^{\mathrm{a}}$ \\
40 & $26.73 \pm 0.01$ & $20.35 \pm 0.00^{\mathrm{a}}$ \\
\hline
\end{tabular}

${ }^{\text {a }}$ Indicates a significant difference between two groups $(p<0.01)$.

$355-611 \%$ and $217-477 \%$, respectively. The WBC (492.67\%) and FBC (383.04\%) of commercial chitosan in the present study were compatible to those reported by Cho et al. (1998) and No et al. (2000).

Table 2 shows the apparent viscosities of extracted and commercial chitosan at various temperatures. The viscosities of both produced and commercial chitosans decreased with increasing temperature, and there were significant differences between the two groups at all degrees of temperature $(p<0.05)$. In a similar study, Jeon, Kamil, and Shahidi (2002) obtained chitosans with 86.40-91.30\% of deacetylation degree and values of 14,57 and $369 \mathrm{cP}$ for apparent viscosities through the deacetylation of chitin extracted from snow crab (Chinoecetes opilio) processing waste. The researchers reported that the chitosan viscosity was closely related to the deacetylation time and that the chitosan reached its highest viscosity with a short deacetylation time.

The colour values of extracted and commercial chitosan are given in Table 3. In colour measurements, chroma, hue and whiteness values were calculated in addition to $L^{*}$ (lightness), $a^{*}$ (redness) and $b^{*}$ (yellowness) values. No significant difference

Table 3

Colour measurement of extracted and commercial chitosan (mean \pm standard deviation of triplicate determinations)

\begin{tabular}{lcc}
\hline & Extracted chitosan & Commercial chitosan \\
\hline$L^{*}$ & $82.74 \pm 0.44$ & $83.14 \pm 0.62$ \\
$a^{*}$ & $-0.23 \pm 0.11$ & $-0.12 \pm 0.00$ \\
$b^{*}$ & $18.49 \pm 0.95$ & $13.58 \pm 0.02^{\mathrm{a}}$ \\
Chroma & $18.49 \pm 0.94$ & $13.58 \pm 0.02^{\mathrm{a}}$ \\
Hue & $-0.51 \pm 1.79$ & $-1.56 \pm 0.00$ \\
Whiteness & $74.69 \pm 0.80$ & $78.35 \pm 0.48^{\mathrm{a}}$ \\
\hline
\end{tabular}

a Indicates a significant difference between two groups $(p<0.01)$.

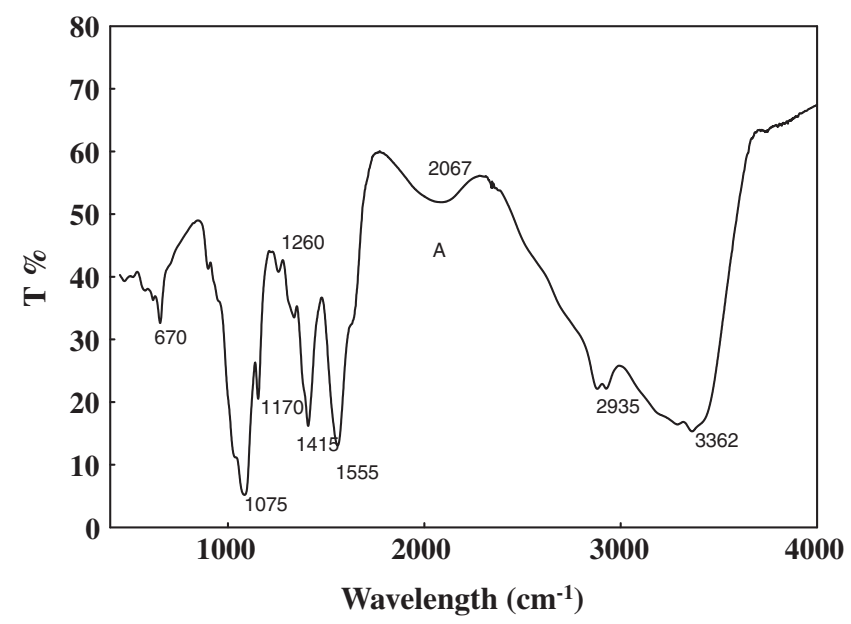

Fig. 1. FTIR spectra of chitosan extracted from shrimp shells. 

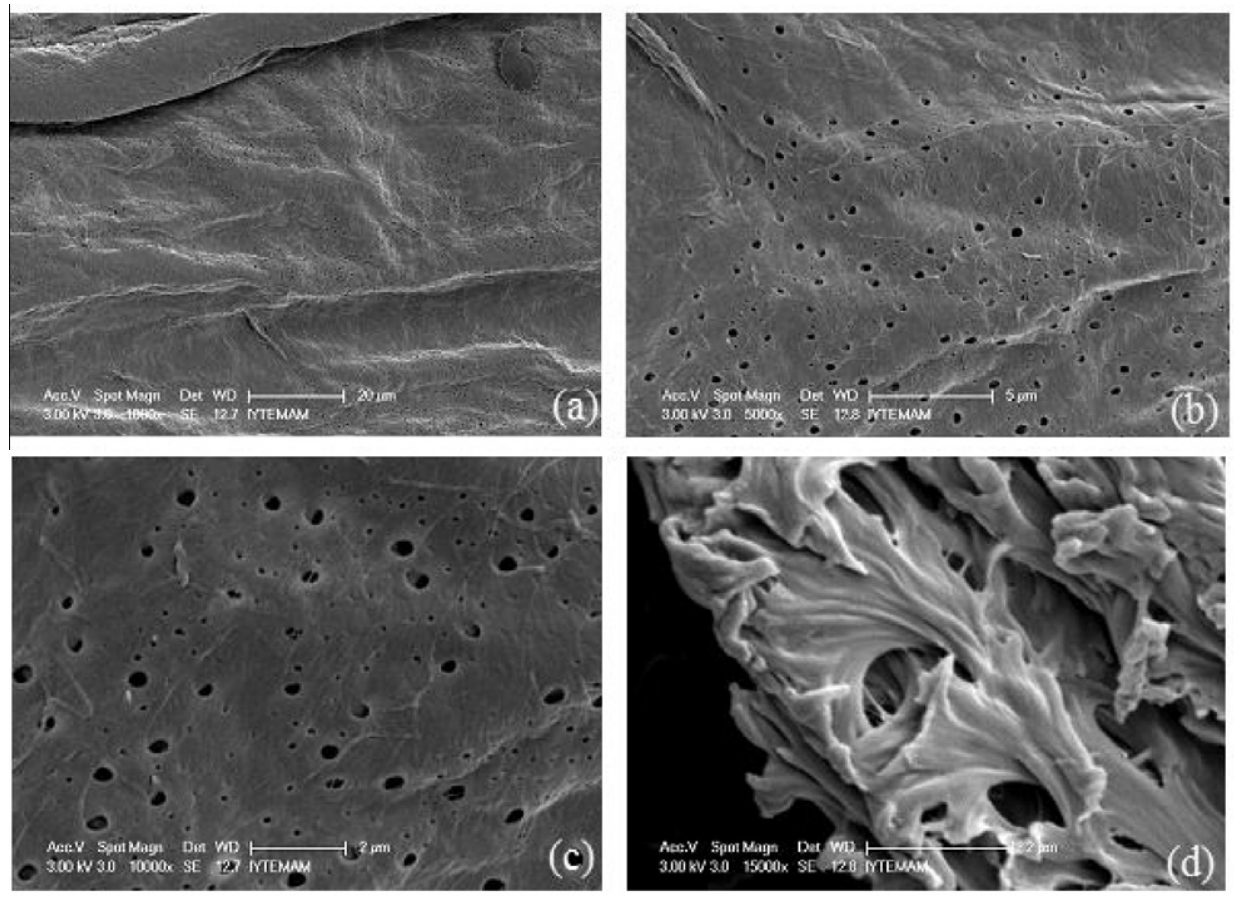

Fig. 2. SEM images of chitosan (a) $1000 \times$, (b) $5000 \times$, (c) $10,000 \times$, (d) $15,000 \times$.

was observed between the $L^{*}, a^{*}$ and hue values $(p>0.05)$, while the $b^{*}$ and chroma values of the chitosan synthesised in the study were found lower compared to commercial chitosan $(p<0.05)$. Similarly, chitosan extracted from crawfish was subjected to ozone application for $20 \mathrm{~min}$ and its $L^{*}, a^{*}, b^{*}$, chroma and hue values were determined as $80.91,-1.82,28.86,25.60$ and 94.17 , respectively. In addition, the colour of chitosan was reported to be associated with the carotenoid pigment astaxanthin (Seo et al., 2007).

Fourier transform infrared spectroscopy was used to determine the structure of chitosan. The infrared spectrum for extracted chitosan is given in Fig. 1. According to this spectrum, the peak observed around $1555 \mathrm{~cm}^{-1}$ is attributed to $\mathrm{N}-\mathrm{H}$ bending of the secondary amide II bands of -CONH-. However, the amide I band, which is usually observed around $1655 \mathrm{~cm}^{-1}$, cannot be observed. Other bands that are observed in the region of $1380-1460 \mathrm{~cm}^{-1}$, are attributed to the symmetric and asymmetric bending vibrations of the methyl groups. According to the study of $\mathrm{Li}$, Weng, $\mathrm{Wu}$, and Zhou (1998) the peak at $1415 \mathrm{~cm}^{-1}$ indicates the $\mathrm{C}-\mathrm{H}$ bending vibrations of $-\mathrm{CH}_{2}$. When the spectra given in Fig. 2 are observed, the small peak around 2900 is ascribed as $-\mathrm{CH}_{2-}^{-},-\mathrm{CH}_{3}$ groups. The $\mathrm{C}-\mathrm{O}$ stretching of structure is observed at $1075 \mathrm{~cm}^{-1}$ according to the literature. The broad band around 3300 is usually attributed to intermolecular $-\mathrm{H}$ bands. The out plane bending $-\mathrm{OH}$ vibrations are observed at $670 \mathrm{~cm}^{-1}$. Strong amide II bands could not be observed, which is due to the high deacetylation degree of the produced chitosan.

The studies in the literature about FTIR spectroscopy related with chitosan show some characteristic peaks, which are at $2940 \mathrm{~cm}^{-1}\left(-\mathrm{CH}_{3},-\mathrm{CH}_{2}\right), 1655 \mathrm{~cm}^{-1}$ ( $\mathrm{C}=\mathrm{O}$ stretch vibration of secondary amide I band), $1555 \mathrm{~cm}^{-1}$ ( $\mathrm{N}-\mathrm{H}$ bending vibration of amide II band), $1570 \mathrm{~cm}^{-1}$ (N-H bending vibration of primary amides) and $1070 \mathrm{~cm}^{-1}$ (C-O stretching) (Choi, Kim, Pak, Yoo, \& Chung, 2007; Lee, Hong, Kajiuchi, \& Yang, 2005).

The morphology of chitosan was studied by SEM and the SEM images with different magnifications and different areas of chitosan are shown in Fig. 2. The extracted chitosan was observed to have layers of flakes, and porous could be seen on some areas. In some parts of chitosan, fibril structures can easily be distinguished.
When the magnification became higher in some parts of chitosan, crumbling flakes were observed with fibril structures as in the study of Yen et al. (2009).

The X-ray diffraction pattern for chitosan was given between 5 and 40 of $2 \Theta$ in Fig. 3. The prepared chitosan has two peaks at $2 \Theta=20.2$ and at $2 \Theta=22.4$, the latter peak is weaker than the first one, whereas, in the literature, many XRD patterns of chitosan have two characteristic peaks which are usually around $2 \Theta=10$ and $2 \Theta=20$ (Yen et al., 2009). The reason of having different characteristic peaks might be caused by the source of chitin, as suggested by Yen et al. (2009). The chitosan chains are shown to crystallize in an orthorhombic unit cell by Okuyama, Noguchi, Miyazawa, Yui, and Ogawa (1997).

The crystal size of samples $(t)$ was also calculated by applying of the following Debye Scherrer equation using the XRD data:

$t=\frac{0.9 \lambda}{\beta \cos \theta}$

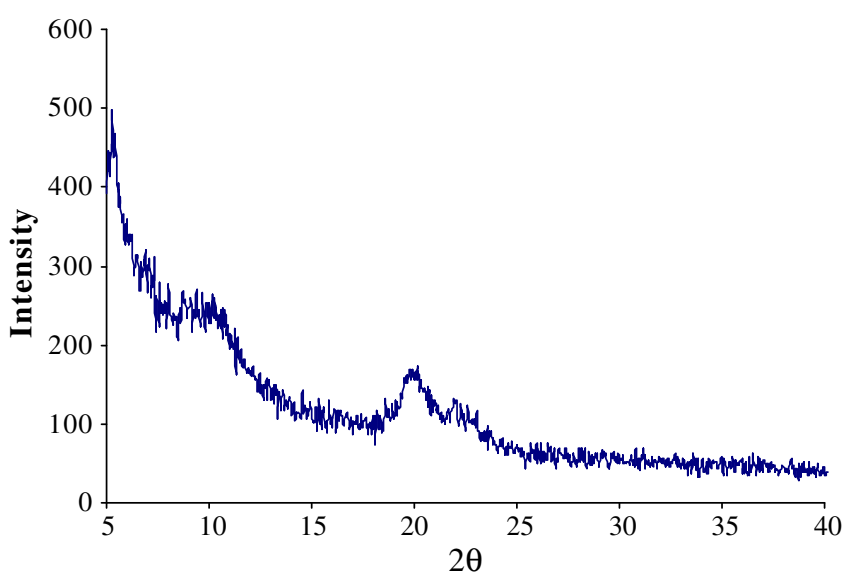

Fig. 3. X-ray diffraction patterns of chitosan extracted from shrimp shells. 
where 0.9 is the shape factor, $\lambda$ is the X-ray wavelength, typically $1.542 \AA, \beta$ is the line broadening at half the maximum intensity in radians, and $\theta$ is the Bragg angle, which is the angle of the incident beam and the lattice plane, which comes from the theoretical basis of the X-ray diffraction. The estimation regarding the crystal size of the sample $(t)$ is calculated as $8.157 \mathrm{~nm}$.

\section{Conclusions}

This study investigated the physicochemical characteristics of chitosan extracted from the shells of M. stebbingi waste, which is discarded without being used and causes environmental pollution. The results of the study were also compared with commercial chitosan extracted from crab. Based on the results it is suggested that there is good potential for the production of chitosan in Turkey, from crustacean shells, which constitute a significant amount of waste in nature, which this way could be prevented.

\section{Acknowledgments}

This study was supported by the Cukurova University Research Fund. The authors would like to thank Izmir Institute of Technology for its contribution during analyses.

\section{References}

Chang, K. L. B., Tsai, G., Lee, J., \& Fu, W.-R. (1997). Heterogenous N-deacetylation of chitin in alkaline solution. Carbohydrate Research, 303, 327-332.

Cho, Y. I., No, H. K., \& Meyers, S. P. (1998). Physicochemical characteristics and functional properties of various commercial chitin and chitosan products. Journal of Agricultural and Food Chemistry, 46, 3839-3843.

Choi, C. Y., Kim, S. B., Pak, P. K., Yoo, D., \& Chung, Y. S. (2007). Effect of N-acylation on structure and properties of chitosan fibers. Carbohydrate Polymers, 68, 122-127.

Coward-Kelly, G., Agbogbo, F. K., \& Holtzapple, M. T. (2006). Lime treatment of shrimp head waste for the generation of highly digestible animal feed. Bioresource Technology, 97, 1515-1520.

Duarte de Holanda, H., \& Netto, F. M. (2006). Recovery of components from shrimp (Xiphopenaeus kroyeri) processing waste by enzymatic hydrolysis. Journal of Food Science, 71(5), 298-303.

Guo, X. F., Kikuchi, K., Matahira, Y., Sakai, K., \& Ogawa, K. (2002). Water-soluble chitin of low degree of deacetylation. Journal of Carbohydrate Chemistry, 21, 149-161.

Healy, M., Green, A., \& Healy, A. (2003). Bioprocessing of marine crustacean shell waste. Acta Biotechnology, 23(2-3), 151-160.

Hongpattarakere, T., \& Riyaphan, O. (2008). Effect of deacetylation conditions on antimicrobial activity of chitosans prepared from carapace of black tiger shrimp (Penaeus monodon). Songklanakarin Journal of Science and Technology, 30(1), 1-9.

Jeon, Y.-J., Kamil, J. Y. V. A., \& Shahidi, F. (2002). Chitosan as an edible invisible film for quality preservation of herring and Atlantic cod. Journal of Agricultural and Food Chemistry, 50, 5167-5178.

Kamil, J. Y. V. A., Jeon, Y.-J., \& Shahidi, F. (2002). Antioxidative activity of chitosan of different viscosity in cooked comminuted flesh of herring (Clupea harengus). Food Chemistry, 79, 69-77.
Kasaai, M. R., Arul, J., \& Charlet, G. (2000). Intrinsic viscosity-molecular weight relationship for chitosan. Journal of Polymer Science Polymer Physics, 38, 2591-2598.

Knorr, D. (1984). Use of chitinous polymers in food. Food Technology, 38(1), 85-97.

Lamarque, G., Cretenet, M., Viton, C., \& Domard, A. (2005). New route of deacetylation of $\alpha$ - and $\beta$-chitins by means of freeze-pump out-thaw cycles. Biomacromolecules, 6, 1380-1388.

Lee, M. Y., Hong, K. J., Kajiuchi, T., \& Yang, J.-W. (2005). Synthesis of chitosan-based polymeric surfactants and their adsorption properties for heavy metals and fatty acid. International Journal of Biological Macromolecules, 36, 152-158.

Li, Q., Dunn, E. T., Grandmaison, E. W., \& Goosen, M. F. A. (1992). Applications and properties of chitosan. Journal of Bioactive Compatible Polymers, 7, 370-397.

Li, Q., Weng, S., Wu, J., \& Zhou, N. (1998). Comparative study on structure of solubilized water in reversed micelles. 1 FT-IR spectroscopic evidence of water/ AOT/n-heptane and water/NaDEHP/n-heptane systems. The Journal of Physical Chemistry B, 102, 3168-3174.

Muzzarelli, R. A. A., \& Rocchetti, R. (1985). Determination of the degree of acetylation of chitosan by first derivative ultraviolet spectrophotometry. Carbohydrate Polymer, 5, 461-472.

Nemtsev, S. V., Gamzazade, A. I., Rogozhin, S. V., Bykova, V. M., \& Bykov, V. P. (2002). Deacetylation of chitin under homogeneous conditions. Applied Biochemistry and Microbiology, 38, 521-526.

Niamsa, N., \& Baimark, Y. (2009). Preparation and characterization of highly flexible chitosan films for use as food packing. American Journal of Food Technology, 4(4), $162-169$.

No, H. K., Lee, K. S., \& Meyers, S. P. (2000). Correlation between physicochemical characteristics and binding capacities of chitosan products. Journal of Food Science, 65, 1134-1137.

No, H. K., \& Meyers, S. P. (1989). Crawfish chitosan as a coagulant in recovery of organic compounds from seafood processing streams. Journal of Agricultural and Food Chemistry, 37(3), 580-583.

Oh, H., Kim, Y. J., Chang, E. J., \& Kim, J. Y. (2001). Antimicrobial characteristics of chitosan against food spoilage microorganisms in liquid media and mayonnaise. Bioscience, Biotechnology, and Biochemistry, 65, 2378-2383.

Okuyama, K., Noguchi, K., Miyazawa, T., Yui, T., \& Ogawa, K. (1997). Molecular and crystal structure of hydrated chitosan. Macromolecules, 30, 5849-5855.

Ruiz-Herrera, J. (1978). The distribution and quantitative importance of chitin in fungi. In: R. A. A. Muzzarelli, E. R. Pariser (Eds.), Proceedings of the first international conference on chitin/chitosan. MIT Sea Grant Report MITSG78-7 Index No. 78-307-Dmb (pp. 11-21). Cambridge: Massachusetts Institute of Technology.

Seo, S., King, J. M., \& Prinyawiwatkul, W. (2007). Simultaneous depolymerisation and decolorization of chitosan by ozone treatment. Journal of Food Science, 72(9), 522-526.

Shahidi, F., \& Synowiecki, J. (1991). Isolation and characterization of nutrients and value-added products from snow crab (Chinoecetes opilio) and shrimp (Pandalus borealis) processing discards. Journal of Agricultural and Food Chemistry, 39, 1527-1532.

Tajik, H., Moradi, M., Rohani, S. M. R., Efrani, A. M., \& Jalali, F. S. S. (2008). Preparation of chitosan from brine shrimp (Artemia urmiana) cyst shells and effects of different chemical processing sequences on the physicochemical and functional properties of the product. Molecules, 13, 1263-1274.

Tolaimate, A., Desbrières, J., Rhazi, M., Alagui, A., Vincendon, M., \& Vottero, P. (2000). On the influence of deacetylation process on the physicochemical characteristics of chitosan from squid chitin. Polymer, 41, 2463-2469.

Wang, Q. Z., Chen, X. G., Liu, N., Wang, S. X., Liu, C. S., Meng, X. H., et al. (2006). Protonation constants of chitosan with different molecular weight and degree of deacetylation. Carbohydrate Polymers, 65, 194-201.

Wang, J. C., \& Kinsella, J. E. (1976). Functional properties of novel proteins: Alfalfa leaf protein. Journal of Food Science, 41, 286-292.

Yen, M.-T., Yang, J.-H., \& Mau, J.-L. (2009). Physicochemical characterization of chitin and chitosan from crab shells. Carbohydrate Polymers, 75, 15-21. 